\title{
A epidemiologia das deficiências nutricionais no Nordeste: a contribuição de Malaquias Batista Filho à institucionalização da Nutrição em Saúde Pública no Brasil
}

\author{
The epidemiology of the nutritional deficiencies \\ in the Northeast: the contribution of Malaquias \\ Batista Filho to the institutionalization of nutrition \\ in Public Health in Brazil
}

No bojo dos acontecimentos econômico-político-sociais e culturais que bastante específico, cuja preocupação central voltava-se para o estudo da complexa e paradoxal problemática da gênese e reprodução da fome/desnutrição e suas formas de enfrentamento. Nesse movimento, destacamos a atuação de dois eminentes cientistas pernambucanos que, desde o início dos anos 30, participavam do processo de constituição do campo da nutrição no Brasil. De um lado, Josué de Castro (1908-1973), à época deputado federal por Pernambuco, que, entre outras contribuições, presidiu, em 1955, o 1o Congresso Camponês de Pernambuco, ocasião em que foi criada a estrutura orgânica e eleita a primeira diretoria do movimento das Ligas Camponesas; fundou, em 1957, a Associação Mundial de Luta Contra a Fome (ASCOFAM) e realizou o Seminário de Endemias e Desnutrição do Nordeste, em junho de 1958, no Município de Garanhuns, PE. De outro lado, Nelson Chaves (1906-1982), que fundou, em 1956, o Instituto de Fisiologia e Nutrição (atual Departamento de Nutrição da Universidade Federal de Pernambuco - UFPE); criou, em 1957, o Curso de Nutricionistas (atual Curso de Graduação em Nutrição da UFPE) e coordenou, em 1963, uma investigação nutricional denominada Northeast Brazil Nutrition Survey, patrocinada pelo Interdepartmental Committee on Nutrition for National Development (ICNND) dos Estados Unidos da América, entre outras contribuições. Ambos irão desenvolver uma forte influência sobre as gerações de cientistas (médicos e nutricionistas) que, nos anos subseqüentes, participaram do processo de institucionalização da Nutrição em Saúde Pública no Brasil1. Dentre estes, destacamos a contribuição de Malaquias Batista Filho.

Malaquias Batista Filho nasceu em 31 de agosto de 1934, no sítio Pitombas, Município de São Sebastião do Umbuzeiro, Cariris Velhos, Estado da Paraíba.

Em 1961, graduou-se em Medicina pela Universidade Federal da Paraíba (UFPB). Enquanto acadêmico, participou do movimento estudan- 
til como secretário de saúde da União Estadual dos Estudantes, tendo, inclusive, atuação junto ao movimento das Ligas Camponesas deste Estado. Em 1964, com o golpe militar, foi demitido de suas funções na UFPB e no Serviço da Assistência Médica Domiciliar de Urgência (SAMDU), nos quais exercia atividades profissionais. Em 1965, especializou-se em Nutrição em Saúde Pública pelo Instituto de Nutrição da UFPE (INUFPE), quando teve início sua trajetória de docente desta instituição, vinculando-se à então Divisão de Nutrição em Saúde Pública (embrião do atual Laboratório de Nutrição em Saúde Pública), onde, entre outras atividades, coordenou os cursos de Nutrição em Saúde Pública para médicos e implantou a Unidade de Campo de Ribeirão, PE, nesta atuando como médico responsável pelo Centro de Educação e Recuperação Nutricional - CERN (1967-1972). Em 1976, concluiu o curso de doutorado da Faculdade de Saúde Pública da Universidade de São Paulo.

Em sua trajetória acadêmico-profissional no atual Departamento de Nutrição da UFPE, além das atividades de ensino de graduação e pósgraduação, destacam-se o desenvolvimento de importantes projetos de pesquisa e extensão e a publicação de dezenas de artigos, capítulos de livros, livros e relatórios técnicos no campo da Nutrição em Saúde Pública. Em relação aos trabalhos publicados ao longo do período compreendido entre 1965 e os dias atuais, a sua produção científica, individual ou em grupo, conta com mais de cem títulos e versa basicamente sobre as seguintes temáticas: inquéritos nutricionais; epidemiologia das deficiências nutricionais (hipovitaminose A, desnutrição energético-protéica, anemias nutricionais e bócio endêmico); recuperação nutricional de desnutridos; avaliação nutricional de crianças e gestantes e sistema de vigilância alimentar e nutricional (SISVAN). Em junho de 1997, no momento de nossa primeira entrevista, permanecia na situação de ativo permanente, exercendo as funções de professor titular do Departamento de Nutrição do Centro de Ciências da Saúde da UFPE, além de vincular-se ao programa de pós-graduação do Instituto Materno Infantil de Pernambuco (IMIP), atividades desenvolvidas até os dias atuais2.

Sua experiência na Unidade de Campo de Ribeirão, onde implantou, sob a orientação do Dr. Ivan Beghin, consultor da Organização PanAmericana de Saúde (OPAS), o Programa de Suplementação Alimentar Supervisada (PSAS), serviu de protótipo para a criação, em 1975, do Programa de Suplementação Alimentar (PSA) do Instituto Nacional de Alimentação e Nutrição (INAN) para todo o país, na gestão do Dr. Bertoldo Kruse Grande de Arruda. Foi o professor Malaquias que elaborou, por solicitação do INAN, a proposta técnica e orçamentária para esse programa, como parte do 2o Programa Nacional de Alimentação e Nutrição (2o PRONAN).

Participou, ainda, de missões internacionais na América Central, como consultor da OPAS, e na África (Cabo Verde, Moçambique), como consultor da FAO.

Enquanto um dos protagonistas da história da gênese e consolidação do campo da Nutrição em Saúde Pública brasileira, Malaquias Batista Filho, com toda competência, sensibilidade e rigor científicos que lhes são característicos, presenteia-nos, nesta entrevista, com importantes relatos orais que, sem dúvida, possibilitarão uma melhor compreensão do processo de transição epidemiológica nutricional, verificado ao longo dessas últimas quatro décadas.

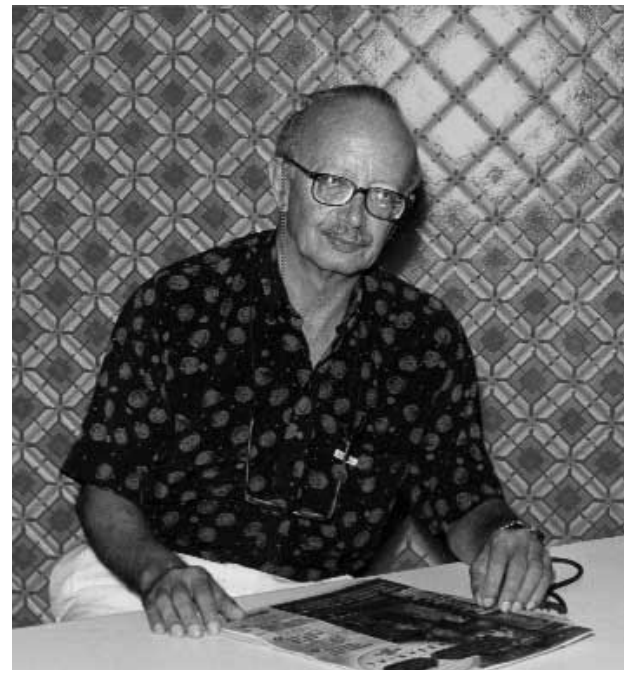

Prof. Malaquias Batista Filho: Depto. de Nutrição, Centro de Ciências da Saúde, UFPE, Recife, abril de 2000. 
Francisco Professor, de início, fale um pouco sobre a sua formação acadêmica em Medicina: quais foram os antecedentes, quando iniciou e concluiu o curso, quem foram os professores, as influências, e como se deu sua participação no movimento estudantil.

Malaquias Eu comecei o curso em 1956 e terminei em 1961, lá na Paraíba. Os antecedentes foram os convencionais dessas famílias de classe média do interior. Minha família acreditava que o curso médico era uma forma de ser bem sucedido, possivelmente de fazer política, de ser candidato a prefeito. Meu pai até queria, quando eu ainda era estudante de Medicina, que eu fosse prefeito de uma cidade do interior (São Sebastião do Umbuzeiro, PB), mas eu quase faço Jornalismo. Trabalhei na imprensa uns quatro ou cinco anos. Tive dúvidas se deveria continuar meu projeto de fazer Medicina.

A respeito dos professores que tiveram influência na minha formação, eu ressaltarei três. Primeiro, o professor Antônio Dias, muito mais pela dedicação que ele tinha aos pacientes. Foi meu professor de Clínica; eu trabalhei na enfermaria que ele coordenava. Em segundo lugar, o professor Bezerra de Carvalho, de Campina Grande. Excelente clínico e com uma formação cultural muito boa, por sinal; foi o melhor clínico que eu conheci na minha vida. E, em terceiro, Eugênio Carvalho. Uma particularidade: era um professor de Bioquímica que gostava muito de Nutrição. Era o único que se interessava por Nutrição, com uma visão muito bioquímica. Tanto é que nós fizemos um trabalho, em João Pessoa, para determinar as proteínas séricas em populações civis e militares. A população civil era composta por trabalhadores que estavam construindo o Grupamento de Engenharia, e os militares eram os recrutas. Surpreendentemente, naquela época, foram encontrados níveis mais elevados de proteína entre os civis do que entre os militares. Depois, isso passou a ter uma explicação. $\mathrm{Na}$ América Central, também foi detectado que em grupos populacionais onde o consumo de proteína é muito de origem vegetal, em condições de vida mais desfavoráveis, a tendência é subir a proteína total, sobretudo, as globulinas.

F E como foi a sua participação no movimento estudantil?

M Bem, eu fui secretário de saúde da União Estadual dos Estudantes, que naquele tempo se organizava como uma espécie de governo paralelo (...). Tinha uma secretaria da saúde, uma secretaria de assuntos culturais, uma secretaria de assistência social, uma secretaria de programação (...). Nesse tempo, eu comecei a organizar dentro da universidade, com o apoio de alguns professores e alguns médicos amigos, os serviços médicos das Ligas Camponesas. Então, era na área de saúde que eu representava o movimento camponês dentro do movimento estudantil.

F Sua atuação nas Ligas Camponesas da $\mathrm{Pa}-$ raíba foi na região de Sapé?

M Era, na região de Sapé. Todo domingo eu ia para Oitizeiro, porque tinha a feira e vinham muitos camponeses da zona de Caxitu, daquele vale que tem um rio que abastece a capital, João Pessoa. Foi quando eu participei da invasão de terra de um proprietário que se chamava Chico das Neves. Foram expulsos uns camponeses de Lucena e eu fiquei com a tarefa de arranjar terras para eles. Invadimos a propriedade que era do Estado e de que esse Chico das Neves se apossou. Assim, durante a minha vida estudantil, eu fui encarregado disso que nós chamávamos, naquela época, de uma ação. Ação era uma tarefa estabelecida por um grupo e pela qual alguém deveria ser responsável.

F Como foi, então, que o senhor se aproximou da Nutrição?

M Ah, sim, eu ainda gostaria de ressaltar uma coisa que diz respeito ao movimento estudantil. Eu também trabalhava no jornal e aproveitava muito a condição de jornalista para pôr em discussão certos temas, fazer determinados movimentos...

F Em que jornal o senhor trabalhava?

M No jornal do Estado, que chamava-se $A$ União. Nós fizemos um movimento no jornal para que acabasse o trote estudantil, porque eu achava aquele negócio violento e absurdo. Isso foi no segundo ano de Medicina. Fizemos também um movimento, ainda na minha condição de jornalista, pela volta à Paraíba dos restos mortais de Epitácio Pessoa, que saiu da Paraíba frustrado pela roubalheira que existia no Estado. Bem, falemos agora da aproximação com a Nutrição. Quando eu estava no quarto ano de Medicina, li Geografia da Fome 3 , e aquele livro foi um divisor de águas para mim. Naquele momento, eu decidi que não seria mais o clínico convencional que tinha sido retratado, que tinha sido caricaturado por minha família e até por mim. Eu queria ser um médico de saúde coletiva e, ao mesmo tempo, também um militante político. Esse livro revelou para mim um mundo que eu nunca tinha questionado. A partir daí, eu passei a me interessar por Nutrição. Nesse ano, eu fui escolhido pela Faculdade de Medicina para representá-la na 16 a Semana de 
Estudos Acadêmicos de Medicina do Brasil, em Ribeirão Preto, São Paulo. Eu levei para esse evento uma contribuição, foi um Flagrante de Inquérito Alimentar em Área Urbana da Paraíba. Era um estudo um tanto voluntarista. Naquela época, eu não tinha noção de amostragem; eu saía na chamada Rua da Pedra, lá em Cruz das Armas, descia-a com um saco de piperazina, que era um comprimido usado então para combater Ascaris. Como grande parte da população tinha Ascaris e o tratamento de verminose era bem aceito, eu entrava na casa, fazia um inquérito de consumo alimentar (semanal) e distribuía comprimidos para o tratamento de ascaridíase. Levei essa contribuição para Ribeirão Preto, foi meu primeiro trabalho na área de Nutrição.

F Isso foi influência dos inquéritos realizados por Josué de Castro?

M Sobretudo por conta do livro de Josué de Castro, Geografia da Fome; depois, por Geopolítica da Fome 4 . Ele influiu muito, até a ponto de eu mudar o próprio estilo de escrever; passei a tentar imitar o Josué de Castro. Trabalhei muito a sua temática e passei a ser um militante de esquerda a partir daquele momento. A leitura do livro, para mim, foi uma iniciação.

F Eu li em uma referência que Josué de Castro presidiu o 1o Congresso Camponês de Pernambuco, quando foi criada a estrutura das Ligas Camponesas, acho que em 1955. Nesse período, ele já estava atuando no Rio, entrando na política como deputado federal por Pernambuco. Achei isso muito interessante. O senhor tem conhecimento disso?

M É provável, mas eu não sabia desse detalhe. Agora, eu sei, por exemplo, que Sete Palmos de Terra e um Caixão 5 , praticamente, é Geografia da Fome com um preâmbulo sobre a história das Ligas Camponesas. Aquele livro foi publicado já depois da "revolução", por conta de duas ou três conferências que ele fez nos Estados Unidos sobre o problema das Ligas Camponesas. Mas eu não sabia que existiam esses antecedentes históricos. Eu imaginava que tinha sido Julião. Julião ${ }^{6}$ me parece que foi muito mais ativo nessa área. Você sabe da história das Ligas Camponesas, não é? De início, o que os camponeses queriam era o direito de se organizar numa liga para comprar um caixão. Isso até é citado em Josué de Castro, em Sete Palmos de Terra e um Caixão. Comprar um caixão para ser enterrado quando morresse. Eles achavam que era uma suprema indignidade morrer e ser enterrado no chão, que eles chamavam de cova rasa. Começaram a se cotizar no Engenho
Galiléia para que, quando morresse alguém, tivessem condições de pagar um caixão. Isso foi crescendo e, quando os proprietários passaram a ter uma percepção do que aquilo poderia significar, começaram a reagir. Julião, como advogado, foi chamado a participar desse movimento, a advogar a organização que eles estavam fazendo. Então, ele percebeu, tal como os proprietários, só que do outro lado, que aquilo poderia ter uma perspectiva maior. E se dispôs a colaborar com essa perspectiva.

F Lembrei a referência. É Fernando Antônio Azevêdo, autor de uma tese de mestrado da UFPE, publicada em forma de livro com o nome As Ligas Camponesas 7 , onde cita a participação de Josué de Castro naquele congresso de camponeses. Mas vamos continuar com a questão da sua aproximação com a Nutrição.

M Então, a partir daí eu passei a me interessar por essa área. Entrei no movimento camponês, entrei na Frente de Mobilização Popular, que era um movimento de Brizola, enquanto as Ligas Camponesas era um movimento de Julião, fundamentalmente por conta da leitura de Josué de Castro. A minha aproximação foi essa.

F O senhor conheceu Josué de Castro, pessoalmente? Que perfil o senhor traçaria dele?

M Ah, sim, conheci. Josué de Castro foi fazer uma palestra na Paraíba, convidado pelos estudantes, e eu o entrevistei, porque naquela época trabalhava no jornal. Nesse encontro, ele me deu uma separata, uma primeira versão de O Livro Negro da Fome ${ }^{8}$, com poucas páginas, umas trinta datilografadas. Falei para ele sobre meu interesse por essa área e tudo o que eu fazia. Depois desse encontro, inclusive, nós mantivemos correspondência. Você me pede um perfil, eu vou fazer uma caricatura muito rápida, porque talvez ele seja um dos brasileiros mais biografados do mundo. Josué de Castro era uma pessoa impressionante, como argumentador e como debatedor. Era um homem que fazia sínteses muito apropriadas, com muita facilidade, com um pensamento crítico muito penetrante. Ele, simplesmente, via as coisas além dessa impressão superficial. Sobretudo, era um homem público muitíssimo convencido de suas idéias. As idéias dele eram referenciais para ele e para quem estava em torno dele. Josué não deixava as coisas na penumbra, ele era muito positivo, discorria com uma clareza muito grande e utilizava imagens, em termos de descrição, para que suas idéias fossem mais claras. Era um homem impressionante. Talvez, juntamente com Gilberto Freyre tenham sido os dois cientistas brasileiros que 
mais influenciaram a nossa geração em termos de pensamento político, naquela época.

F E como é que o senhor chegou a Pernambuco, no Instituto de Nutrição?

M Olha, essa é uma história muito complicada. Em 64, quando houve a "revolução", eu fui demitido da UFPB e do SAMDU, onde eu trabalhava. A criação do SAMDU, de certa forma, estava ligada ao movimento camponês. Quando mataram João Pedro Teixeira ${ }^{9}$, o presidente João Goulart visitou a Paraíba e perguntou o que poderia ser feito imediatamente para aliviar as tensões na região. Reforma agrária não dava para fazer imediatamente. Poderia ser criado um serviço para dar assistência aos camponeses nas áreas onde tinham as Ligas. Naquele momento, sete cidades tinham Ligas Camponesas, nas quais foram criados sete SAMDUs. Eu fiquei no SAMDU de Santa Rita. Então, eu tinha dois empregos públicos, a universidade e o SAMDU, onde dava um plantão semanal. Fui demitido e não tinha, de forma nenhuma, mais campo no Estado da Paraíba. Eu li uma notícia no jornal que estava sendo oferecido um curso de Nutrição em Saúde Pública, era o segundo a ser oferecido aqui no Departamento de Nutrição. Nesse curso, os candidatos deveriam apresentar uma indicação. Eu estava num momento em que ninguém queria me indicar. Eu era qualquer coisa como um leproso - vou usar essa expressão - na Idade Média, ninguém queria aproximação. Mesmo os professores que eram muito meus amigos não queriam.

F Isso devido à sua atuação política?

M Era. Tinha havido a "revolução" e ninguém queria se comprometer. E, assim, eu tive que me aventurar e aparecer lá sozinho. Apareci aqui e Nelson Chaves me disse que havia ainda duas ou três vagas nesse curso. Então, eu me inscrevi como médico voluntário. E, no final do curso, Nelson Chaves me chamou para ficar trabalhando aqui.

F Isso foi em 65 ?

M Foi em 65, devia ter uns oito ou dez meses depois da "revolução". Eu imaginava que ele não sabia do meu passado político, mas disseram para ele e mesmo assim ele me acatou. Por isso, eu tenho uma reverência muito grande a Nelson Chaves. Ele tinha uma formação política mais conservadora, era ligado, historicamente, à monocultura da cana-de-açúcar. $\mathrm{O}$ pai dele, Eurico Chaves, tinha sido, eu creio, senador. Era dono de um engenho, o Engenho Vênus. E o irmão dele era co-proprietário da maior usina de açúcar de Pernambuco e da América
Latina, a Catende. No entanto, ele sabia que eu era militante da esquerda e me acolheu. Essa foi a história de como eu cheguei aqui.

F O senhor poderia continuar falando sobre Nelson Chaves, traçando um perfil dele?

M Nelson Chaves era, fundamentalmente, um acadêmico, um homem de laboratório. Sua formação era a Fisiologia. Aliás, Josué de Castro também trabalhava com Fisiologia. Naíde Teodósio também trabalhava com Fisiologia. Naquela época, quem trabalhava com Nutrição era, basicamente, fisiologista. Além disso, ele era clínico, dedicado à Endocrinologia. Como clínico, ele fazia Endocrinologia, como professor, trabalhava com fisiologia. O espaço dele era a academia; ele gostava muito de publicar trabalhos com um enfoque experimental. Era um homem de biotério, era um homem de laboratório, que, paradoxalmente, depois da "revolução", começou a se preocupar muito mais intensamente com o social. Foi depois de 64 que Nelson Chaves começou a se preocupar com Saúde Coletiva, criou a Unidade de Campo de Ribeirão, passou a se preocupar com diagnósticos epidemiológicos sobre problemas nutricionais e a trabalhar com intervenções nutricionais de campo. Contrariando um pouco a história do Instituto de Fisiologia e Nutrição e até sua história pessoal de clínico e de pesquisador, a bem lhe digo, em Nutrição Experimental.

F E quais foram as influências que o fizeram, de certa forma, tomar esse outro rumo?

M Bem, acredito que aconteceram várias coisas simultâneas. Uma foi o desafio representado pelo inquérito nutricional patrocinado pelo governo norte-americano, que, em 1963, através do ICNND10, consultou Nelson Chaves para fazer um trabalho de parceria que deveria estabelecer um diagnóstico nutricional do Nordeste brasileiro. O segundo fato, na minha maneira de ver, derivou desses cursos de Nutrição em Saúde Pública, que eram ministrados aqui. Nelson Chaves discutiu muito com a OPAS (Organização Pan-Americana de Saúde). A OPAS questionava que o enfoque deveria ser muito mais amplo, que não se interessaria muito pelo laboratório em si, pela pesquisa interna com animais de biotério. O que interessaria seriam as pesquisas de intervenção, sobretudo, em nível de população. E o terceiro ponto foi a vinda para o Departamento de Nutrição de um consultor da OPAS, Ivan Beghin, um belga, que tinha tido uma experiência na África, no Haiti. Aqui no Departamento, Beghin passou a defender a idéia de que nós deveríamos ter um novo espaço de trabalho, que seria a Saúde Co- 
letiva. E o quarto, aliás, em ordem cronológica seria o terceiro ponto, foi a criação de uma unidade de campo no interior, a Unidade de Campo de Ribeirão, com base em um projeto que resultava do diagnóstico feito pelos americanos com o Departamento de Nutrição, em 63. Era um projeto de combate à hipovitaminose A, através do enriquecimento do leite desengordurado com vitamina $\mathrm{A}$, em nível domiciliar.

F Esse leite desengordurado já era o fornecido pelo programa Alimentos para a Paz, da USAID (United States Agency for International Development)?

M Olha, a essa altura, eu creio que era da USAID. Se bem que era a continuação de um projeto anterior, chamado de projeto FISI. O FISI, desde 47, mais ou menos, distribuía leite em pó. Quando terminou a Segunda Guerra Mundial, criou-se o FISI, hoje UNICEF (Fundo das Nações Unidas para a Infância). Era Fundo Internacional de Socorro à Infância, mas o que se fazia, concretamente, era distribuir leite em pó. Em 64, eu creio que era a USAID que estava operando aqui no Brasil, mas esse projeto era financiado pela General Food Corporation, uma instituição americana, não sei se ligada à USAID. Eles ficaram muito em cima de que o problema nutricional número um que nós tínhamos era a hipovitaminose A e financiaram o projeto por um ano. Quando Beghin chegou aqui, nós estávamos concluindo esse projeto e criamos o Centro de Educação e Recuperação Nutricional, exatamente na mesma Unidade de Campo. Eu creio que esses quatro fatos, aliados a um pouco da influência de Fernando Figueira, foram decisivos na mudança de direção de Nelson Chaves.

F Nessa época, o IMIP já havia sido criado? M Ah, já. Olhe, o IMIP parece que foi criado em 60 ou 61, uma dessas datas. Foi mais ou menos simultâneo à criação do Departamento de Nutrição. Havia a idéia, inclusive, de que esse piso superior do departamento fosse uma unidade de tratamento de desnutridos. Por outro lado, criou-se uma discussão muito grande, a essa altura, sem a participação da esquerda, que estava proscrita, sobre o problema da fome. A USAID veio distribuir alimentos aqui, porque, reconhecidamente, essa era uma área de população carente. E Nelson Chaves tornouse uma espécie de porta-voz da área de Nutrição. Naíde Teodósio não podia falar, os outros não podiam falar, Josué de Castro estava exilado do Brasil. Ele tornou-se um porta-voz natural desse tema e eu creio que isso implicou a mudança dele para a área de Saúde Coletiva.
Além do que, ele tinha sido secretário de saúde de Pernambuco, no governo de Barbosa Lima Sobrinho.

F Após a conclusão do curso de Especialização em Nutrição em Saúde Pública, como foi a sua inserção no Departamento de Nutrição?

M Bem, a partir daí, eu coordenei o curso de Nutrição em Saúde Pública do ano seguinte. Nós criamos a Unidade de Campo de Ribeirão, onde eu passei quatro a cinco anos (...). Nessa unidade, nós fizemos um trabalho com vitamina A, depois passamos para os CERNs e depois para o Programa de Suplementação Alimentar Supervisada (SAS), uma sigla criada por Beghin.

F Essa unidade servia de base de estágio para os estudantes de Nutrição?

M Ah, sim. Nelson Chaves tornou obrigatório que os estudantes de Nutrição passassem por essa unidade. Estudantes de Sociologia e alguns de Medicina também passaram por lá. Naquele tempo, começou-se a organização do que seria a proposta de Atenção Primária em Saúde. Esse trabalho começou na zona rural, com uma participação conjunta da Fundação Nacional de Saúde (FNS) e da EMATER (Empresa de Assistência Técnica e Extensão Rural) 11 . Era um serviço de extensão rural que a Secretaria de Agricultura juntamente com o Governo Federal mantinham. O pessoal da EMATER recebia um treinamento aqui no Departamento de Nutrição e a Nutrição começou a espalhar-se também na zona rural do Rio Grande do Norte. Foi uma experiência interessante. Apesar de todos os erros, permitiu a aplicação de uma grande variedade de atividades alternativas na área de Nutrição. Foi lá que nós fizemos a primeira vacinação em pobres contra sarampo, porque, naquela época, vacina era praticamente um produto só para ricos. A Organização Mundial de Saúde (OMS) mandou um lote de vacina, por Rueda Williamson, um coordenador do setor de Nutrição da OPAS, que na época visitou a Unidade de Campo de Ribeirão. A OMS mandou dez mil doses da vacina. Como nós só precisávamos de 1.500 doses, tivemos de começar a trabalhar com as áreas vizinhas. Foi uma época muito rica em experiências, a época dessa unidade de campo.

F Professor, vamos retomar a questão da pesquisa norte-americana do ICNND. O senhor poderia falar um pouco mais sobre essa pesquisa?

M Essa pesquisa significou muito para o Departamento de Nutrição, até porque eu a relacionei entre os fatos históricos que devem ter 
contribuído para mudar a linha de pesquisa do departamento. Agora, a pesquisa tinha muito mais propósitos políticos do que, propriamente, científicos. Ela estava ligada a esse grupo do ICNND, estava ligada ao Departamento de Estado dos Estados Unidos da América. Esse D (da sigla) era de "defesa", depois que aconteceu o "golpe de Estado" no Brasil, passou a ser de "desenvolvimento". Essa pesquisa foi interessante em termos de romper a inércia e, até, vamos dizer, romper um paradigma. A Nutrição era desenvolvida majoritariamente dentro de laboratórios. E passaram a ter outra visão, outro tipo de interesse. Mas ela tinha, nitidamente, uma conotação política. Os estudos feitos pelo ICNND, naquela época, foram, sobretudo, em países com problemas políticos: Colômbia, Equador, Bolívia, Paraguai e Chile; em vários países da América Central, Honduras, Guatemala e El Salvador e, antes de entrarem no Vietnam, fizeram também na Malásia e nas Filipinas. Enfim, no mundo inteiro.

F No caso do Brasil, do Nordeste brasileiro, o momento da pesquisa também era bastante sugestivo, tinha o movimento das Ligas Camponesas e parece que eles só atuaram no Nordeste, não é?

M Era bem sugestivo e eles só atuaram no Nordeste. Agora, do ponto de vista de amostragem da pesquisa, a deles não era nada representativa. Eles passavam dois a três meses em cada país, daria até para fazer estudos melhores, com amostras representativas. Mas eles trabalhavam muito com a clientela dos serviços de saúde e, provavelmente, foi esse tipo de clientela, essa metodologia (de seleção amostral) um tanto enviesada, que levou à conclusão de que o principal problema nutricional do Nordeste brasileiro seria a deficiência de vitamina A. No relatório da pesquisa, eles dizem, logo na primeira página, que o problema nutricional número um do Nordeste brasileiro seria esse. Então, essa pesquisa do ICNND tem, sem dúvida, uma importância histórica. Mas se você perguntar se tem uma importância epidemiológica, é duvidoso responder que sim.

F Professor, vamos voltar ao Programa Alimentos para a Paz. O senhor teve alguma experiência com esse programa?

M A experiência que tive com o grupo do Programa Alimentos para a Paz é que eles mandaram 10 ou 12 voluntários para a Unidade de Campo de Ribeirão, e eu fui encarregado de fazer um treinamento com esse pessoal. A despeito de toda idiossincrasia ideológica que eu tinha, achei muito interessante essa experiên- cia, porque nós editamos, naquele momento, um instrutivo em três línguas ("ruralês", português e inglês) sobre as doenças mais comuns da região, inclusive, sobre o kwashiorkor, que era muito comum naquela época. Assim, quando eles encontravam um caso de kwashiorkor na zona rural, logo encaminhavam para a gente. Foi assim que percebemos que o kwashiorkor tinha uma fase estacional (sazonal). Aí matamos uma das charadas do inquérito do ICNND, pois eles trabalharam aqui durante a entressafra da Zona da Mata, período em que mais aparecia a desnutrição, inclusive, o kwaskiorkor. Nós enfrentávamos o problema de como reidratar a criança com kwashiorkor, com marasmo, e a criança de uma maneira geral. Na área rural, não existia, praticamente, nenhum tipo de assistência. Então, nós aproveitamos esse pessoal (eram quase todos de nível universitário), que deve ter contribuído um pouco, nessa linha assistencialista, para encaminhamento de alguns dos nossos problemas. A despeito da mensagem e do interesse político de que eles eram portadores, eu aprendi uma coisa com eles: os estudantes e os profissionais americanos chegavam aqui e iam para o campo, os nossos não iam, era um grande problema levar nossos estudantes e profissionais para o campo. É claro que eles deviam estar ali com motivos muito fortes; na época, eram os Estados Unidos contra a Rússia. Com os brasileiros, nem os que eram pró nem os que eram contra tinham uma atividade militante deste tipo. Pelo menos, eu aprendi com eles essa disposição de militante.

F Professor, ainda em relação ao Programa Alimentos para a Paz, existem algumas referências, ou mesmo um folclore, sobre a questão dos alimentos distribuídos (o leite desengordurado) e casos de cegueira no Brasil. O que o senhor sabe sobre isto?

M Ah, sim. Outra coisa era o que eles traziam. Eu fui uma das pessoas contra isso daí, porque eles traziam produtos, por exemplo, um tal de bulgor, que era uma espécie de trigo, milho ou arroz amassado, pré-triturado, utilizado para fazer papa. Quer dizer, era um produto que não participava dos nossos hábitos culturais. Além do fato de que tudo aquilo chegava num momento em que o problema era anestesiar politicamente, era funcionar como pára-choque, em relação aos conflitos políticos que o Brasil vivia naquela época. Por exemplo, o processo de cooptação da população por prefeitos do interior. Obras de determinadas prefeituras eram pagas com recursos do Programa Alimentos para a Paz. Os prefeitos inscreviam pessoas pa- 
ra executar obras e cerca de $60 \%$ a $70 \%$ do salário era pago através desses alimentos. Há também comentários de que muitas pessoas usavam esses alimentos para a criação de animais, como galinhas e porcos.

F E o caso do leite desnatado, distribuído com cápsulas de vitamina A, foi desse período? Dizem que a população não consumia as cápsulas de vitamina.

M Não, o leite desnatado, com cápsulas de vitamina A, tem uma história prévia, pois o FISI já fazia essa distribuição. Mas, é claro, que naquele momento se difundiu. Eu me lembro que um dos meus professores, meu professor de puericultura, João Soares, lá na Paraíba, fez uma experiência em Cruz das Armas, num posto de puericultura que ele tinha. Ele dava uma sopa aos "meninos" (dada no próprio posto) e distribuía leite e cápsulas de vitamina A, do FISI, muito antes da chegada dos Alimentos para a Paz12. Em nível de justiça doméstica, a mãe interpretava da seguinte forma: - "Por que é que eu vou dar leite e dar também vitamina para o mesmo menino? Então, eu dou leite a um menino e vitamina a outro que não recebeu leite!" Provavelmente, esse foi um dos fatores que contribuíram para que aparecesse uma freqüência muito grande de lesões oculares por deficiência de vitamina A, detectadas aqui em Pernambuco. Detectadas, eu creio que, também, em Santa Catarina, em Fortaleza. E isso passou a ser uma achado comum, por causa da massificação do uso do leite em pó desnatado e das cápsulas de vitamina A.

F O senhor poderia fazer uma avaliação dos CERNs. Há alguma referência de que os CERNs foram desativados em virtude do alto custo operacional? O que o senhor diz sobre isso?

M Esses centros nasceram de uma proposta teórica de um consultor da OMS, José Maria Bengoa. Bengoa propôs, esquematicamente, que as crianças com desnutrição de terceiro grau, segundo a Classificação de Gomez, fossem tratadas em hospital; que as com desnutrição de segundo grau fossem tratadas em CERNs; que aquelas com primeiro grau fossem beneficiárias de um programa de suplementação alimentar e que as normais simplesmente recebessem orientação alimentar. No Haiti, Ivan Beghin e um médico haitiano, Fougere, começaram a operacionalizar essa proposta através dos CERNs. Eles decidiram fazer o seguinte: terceiro e segundo graus de desnutrição, sem complicações, que justificassem a internação hospitalar, seriam tratadas através dos CERNs. E as crianças com primeiro grau, irmãs daquelas assistidas pelos CERNs, tal como propôs Bengoa, receberiam alimentos complementares para serem tratadas em nível domiciliar. Além disso, o CERN seria utilizado como uma forma de fazer com que a mãe da criança, participando dessa experiência, se educasse sobre problemas de alimentação. Ivan Beghin chegou aqui com uma proposta muito ortodoxa; não queria, inclusive, que fosse prestada assistência médica às crianças. Exatamente para ressaltar a ênfase na questão alimentar, para que a experiência de recuperação da criança fosse mais rica no sentido de induzir a mãe a reconhecer que o problema era alimentar. $\mathrm{Eu}$ fui uma das pessoas que reagiram e disse ao Beghin que não dava para implantar esse esquema aqui, porque a população não iria aceitar que tivesse um médico e não cuidasse dos aspectos de saúde. Eu falei que não me sentiria bem dentro de um serviço sem trabalhar os aspectos curativos e até preventivos de saúde, por conta da ortodoxia de uma mensagem educacional. Ao final, ele acabou concordando comigo. Nós começamos esse tipo de experiência, trabalhamos cerca de três ou quatro anos com isso. Esses CERNs foram desativados por duas razões. Em primeiro lugar, porque, quando eu saí de lá - fui fazer o curso de doutorado em São Paulo -, não tinha médico para ir para o interior.

F O senhor ficou apenas no CERN de Ribeirão? M Não, eu trabalhava em Ribeirão mas fazia treinamento, junto com as nutricionistas, do pessoal para outros centros.

F E a experiência expandiu-se para outros Estados, não é?

M Ah, expandiu-se para o Ceará, Rio Grande do Norte, Alagoas, Goiás e eu creio que para a Bahia também. Agora, com a minha saída, cerca de um ano depois, fechou-se a Unidade de Campo de Ribeirão, e aí o CERN foi desativado. Mas eu não veria o CERN, inclusive naquela época, como um bom instrumento. Acho que foi um bom instrumento de aprendizado para a gente. Nós, depois, fizemos uma avaliação e verificamos que não seria tanto o problema de custo, quando comparado, por exemplo, ao custo hospitalar. Nessa avaliação nós pegamos os dados do CERN, os dados do IMIP sobre recuperação de crianças desnutridas e os dados dos programas de suplementação alimentar que incluíam casos de segundo e terceiro graus. Nós vimos o seguinte: segundo e terceiro graus também podem ser tratados, desde que não tenham complicação, dentro dos serviços ambulatoriais. O que é possível é que a gente tenha 
como necessidade cinco a seis dias dentro do hospital. Talvez tenha até necessidade, em alguns casos, de ter algo como um centro de recuperação, não de quatro meses como se fazia antes, mas até que se consolide uma fase inicial de cura ou até que se consolide uma conduta da mãe em relação a isso. Mas não como um espaço que deve concluir todo o ciclo da recuperação da criança desnutrida e de acompanhamento dos irmãos13. Então, foi um pouco essa crítica que levou à própria experiência do INAN (Instituto Nacional de Alimentação e Nutrição). Fui eu quem fez o primeiro orçamento do INAN, no que diz respeito à distribuição de leite e de outros alimentos. Isso foi feito com base na experiência que nós tínhamos com os irmãos de crianças desnutridas e depois com o tratamento de segundo e terceiro graus em serviços de saúde, e não mais em CERNs. Graças aos quatro anos que passamos no CERN de Ribeirão é que foi possível a gente ter elementos para analisar de uma forma mais consistente, com dados empíricos, o que poderia ser uma proposta de distribuição de alimentos através dos serviços de saúde.

F Então, o senhor poderia continuar falando sobre o INAN, sobre a participação do Dr. Bertoldo Kruse de Arruda, de Malaquias Batista Filho, do grupo de Pernambuco no INAN?

M Naquele tempo, eu estava em São Paulo fazendo o doutorado. (...) Isso foi em torno de 74, mais ou menos, e foi o Bertoldo quem acabou indo para o INAN. (...) Eu fiz um bilhete para Bertoldo apontando quais seriam, a meu ver, as grandes prioridades da Nutrição: anemia, hipovitaminose A, a questão do bócio, a questão da desnutrição e o incentivo ao aleitamento materno. Então, Bertoldo disse: "Além de incluir isso eu quero que você venha aqui, passe uma semana". E foi durante essa semana que nós formulamos o programa de suplementação alimentar, chamado Programa de Nutrição em Saúde (PNS), que tinha várias atividades, uma delas, especificamente, a distribuição de alimentos. O PNS nasceu da experiência que nós tivemos, não devidamente avaliada, de trabalhar com os irmãos de crianças desnutridas. E esse programa, conceitualmente, surgiu com base na visão de Beghin e de um argentino consultor da OPAS, Mário Eisler, que tinham concebido a idéia da chamada "criança contato" e da "família vulnerada”. Era o conceito de risco usado em doenças infecciosas que passava a ser utilizado dentro da família (dentro da $\mathrm{Nu}$ trição). Essa foi, mais ou menos, a base que o INAN incorporou. Agora, o PRONAN (Programa Nacional de Alimentação e Nutrição) era muito mais do que isso. O INAN tinha três linhas de atuação. Uma primeira linha de atuação era a racionalização do sistema de produção e distribuição de alimentos que estava mais próxima do pólo de produção e do fluxo de comercialização. O trabalho era realizado com pequenos produtores que, fundamentalmente, operavam com alimentos básicos para a população (como feijão, milho e arroz). Além disso, procurava-se interferir um pouco na cadeia de comercialização através de convênios com os pequenos comerciantes de alimentos, os chamados bodegueiros. A segunda linha era a suplementação alimentar que tinha vários componentes, o PNS, o programa de distribuição de alimentos na rede escolar, que era o já bem consolidado Programa de Merenda Escolar; o programa de alimentação do pré-escolar que tinha sido concebido em São Paulo, por experiência do professor Yaro Gandra. E, finalmente, o terceiro pólo que era a linha de complementação e apoio. Nessa linha, entrava a pesquisa, a formação de recursos humanos e o combate às carências nutricionais específicas. Então, parece-me que o 2o PRONAN, pelo menos em termos de concepção, foi um avanço para aquela época. Aliás, naquela época, dentro do regime militar, havia três programas que eram considerados como consistentes: o PRONAN, o PIASS (Programa de Interiorização das Ações de Saúde e Saneamento) e a CEME (Central de Medicamentos). Esses eram os programas que pareciam ter sentido naquela época.

F Professor, quanto à idealização do 2o PRONAN, do chamado discurso tecnicamente competente e progressista, quem foi que montou essa visão global? Foi o Instituto de Nutrição? Houve influência de Nelson Chaves?

M Talvez a maior influência daqui do Instituto de Nutrição tenha sido na linha de distribuição de alimentos; nas outras áreas, a influência foi menor. Um outro presidente do INAN, Eduardo Kertz, uma das pessoas que participaram da elaboração do 2o PRONAN, também dizia que foi assim. Mas foi um pouco de influência do Banco Mundial, que concedeu empréstimo ao governo militar para a montagem do programa. Teve a influência de Alan Berg e de Alberto Carvalho da Silva, consultores do Banco Mundial. O Banco Mundial estava muito impressionado com o fato de que o Brasil estava indo muito bem economicamente, nós estávamos vivendo a chamada fase do milagre econômico brasileiro; entretanto, a mortalidade infantil estava crescendo. Ao mesmo tempo, em São Paulo, por essa época, surgiu um livro da Pastoral da Criança que mostrava, entre outras 
coisas, que a população de baixa renda estava numa situação bem pior do que no momento em que houve a "revolução". Teve também um terceiro argumento, o fato de que em 74/75 foi feito o ENDEF (Estudo Nacional de Despesa Familiar). Os militares acreditavam que o Brasil tinha mudado e os dados do ENDEF mostravam que não, tanto que os dados passaram a ser vigiados, porque os militares pensavam haver dados de um Brasil que eles não queriam que fosse revelado.

F Só a partir de 77/78 é que os dados do ENDEF começaram a ser publicados, não foi?

M É, só depois. Inclusive, porque começou também a reduzir a mortalidade infantil. E também pelo fato de que o milagre brasileiro começou a se esvaziar. Eu acho que o INAN foi criado com base nisso. Além disso, no empréstimo que o Banco Mundial concedeu ao Brasil estava implícita a necessidade de se preocupar com a área social, com a área da saúde, em face da imagem de um Brasil que estava indo muito bem economicamente, mas pessimamente sob o ponto de vista social.

F No livro Pró-Memória14, editado em 85, o senhor faz um balanço, uma avaliação global do que foi esse período do PRONAN. Hoje, como é que o senhor analisaria a experiência do 2o PRONAN?

M É, mas esse livro foi muito mais uma visão interna do próprio INAN e do próprio Bertoldo Kruse. Apesar de tudo isso, eu creio que o 2으 PRONAN foi a fase mais fecunda do INAN. Você tinha, nas reuniões do INAN (do conselho consultivo), gente do Ministério da Agricultura, do setor de abastecimento e assistência técnica rural; da área do Planejamento; do Ministério da Saúde e do Ministério da Educação. Hoje, o INAN só tem gente da área da Saúde e, mesmo assim, um grupo muito limitado. Existia, naquela época, uma consulta bem ampla aos profissionais que trabalhavam na área de Nutrição dentro do Brasil, e isso se reduziu muito.

F Eu acredito que, de 84 para cá, a tendência foi o esvaziamento do INAN, até a própria extinção recente, o senhor não concorda? Como o senhor avalia essa medida recente de extinção do INAN?

M O INAN, naquela época, tinha um discurso que todo funcionário sabia, que todo o Brasil sabia. Hoje pergunta-se: qual é o discurso do INAN? Não tem, restringiu-se muito. Eu creio que a proposta de extinção pode ser politicamente boa, na medida em que, praticamente, desde 84 , o INAN vivia como um paciente ter- minal. Eu acho que politicamente não se tinha muito o que fazer com o INAN. Agora, no meu modo de ver, foi péssimo, já que se extinguiu o INAN e não foi criado nenhum outro órgão de nível central. Eu acredito que tem de ter um grupo para formular políticas, para estabelecer determinadas diretrizes e parâmetros de programas, de formação de recursos humanos e de supervisão. Ou seja, tem que ter um fórum de debates e até de decisões de caráter nacional, que deve ficar no nível central. Eu creio que acabar com o INAN e não ficar nada, simplesmente colocar recursos no nível dos Municípios, dos Estados, não dá, teria que ter uma instância central. E o raciocínio é relativamente simples: das 15 metas prioritárias de saúde no mundo, um terço é meta de Nutrição. E não é possível que se apague isso no nível central, da mesma maneira que o nível central não se desliga da vacinação, da diarréia, da tuberculose, do pré-natal, da hanseníase. Ou seja, tem que ter uma instância de consulta, de decisão, de orientação, de direcionamento.

F Acompanhando a sua trajetória acadêmica, nós observamos que a epidemiologia da hipovitaminose A no Nordeste, particularmente em Pernambuco, aparece como uma das temáticas centrais da sua produção científica. Fale um pouco sobre suas pesquisas nessa área. Essa temática continua despertando seu interesse, atualmente? Por quê?

M Como eu já comentei anteriormente, os estudos iniciais sobre o problema da vitamina A no Nordeste derivaram do que poderíamos chamar de demanda externa. Em 1965, o ICNND publicou o relatório Northeast Brazil: Nutrition Survey, concluindo que a hipovitaminose A seria o principal problema nutricional da região. Ousadamente, publicamos um artigo de revisão bibliográfica, assumindo que a situação não seria assim, havia um equívoco crucial no inquérito e em suas conclusões. Dois anos depois, ainda por conta do relatório do ICNND, participamos de um estudo de coorte com intervenção (leite desengordurado enriquecido com vitamina A), objetivando a correção dos níveis baixos de retinol sérico de crianças da Zona da Mata de Pernambuco. Foi uma pesquisa desenhada por uma fundação norte-americana. Um terceiro estudo, já na década de 70 , consistiu na aplicação de megadoses de vitamina A (200.000 UI) em pré-escolares da área açucareira, com a orientação técnica e apoio financeiro da OPAS, através de seu consultor, William Simonds.

Atualmente, nosso interesse consiste em avaliar, de forma mais consistente, a própria 
magnitude do problema da hipovitaminose A nas regiões Norte e Nordeste e identificar alguns fatores de risco mais relevantes. Estamos também desenvolvendo ou interessados em ensaios sobre sua aplicação supletiva (doses massivas e enriquecimento de alimentos ou preparações culinárias) como alternativa tecnológica para o controle do problema ou como estratégia auxiliar no tratamento de anemias. $\mathrm{Na}$ realidade, isso se inscreve num questionamento maior: os novos papéis de vitamina A na nutrição humana.

F Outra temática central, desde o início de sua trajetória acadêmica, é a epidemiologia da anemia nutricional. Fale um pouco sobre suas pesquisas nessa área. Essa temática continua despertando seu interesse atualmente? Por quê?

M Embora considerada como uma deficiência específica, a anemia nutricional é uma manifestação sindrômica, com muitos fatores envolvidos em sua gênese. Em termos de prevalência, é o problema nutricional de maior magnitude no Brasil e no mundo, ocorrendo em quase $40 \%$ da população humana, com variadíssimas conseqüências.

As metas internacionais para o combate a essa deficiência, na década de 90, representavam o mais modesto de todos os compromissos dos governos no campo da Nutrição: redução de um terço da prevalência no grupo de gestantes. Além do baixo status político, as anemias enfrentam restrições do próprio know how técnico para o seu controle. Estamos, com vários outros estudiosos, trabalhando neste espaço compreendido pela identificação de fatores e acúmulo de experiências para o controle do problema. Tratamento semanal, enriquecimento de alimentos, adesão aos esquemas de prevenção e terapêutica, avaliação de custos e de eficácia, são os pontos que centralizam nossos interesses e linhas de atuação.

F Quais as atuais linhas de pesquisa e/ou de intervenção nutricional que estão sendo desenvolvidas sob sua orientação/coordenação? M Epidemiologia dos problemas nutricionais, sistemas de vigilância alimentar e nutricional, intervenções para o controle da hipovitaminose A e das anemias, métodos de avaliação do estado nutricional de gestantes, são as principais linhas de abordagem com que estamos comprometidos.

F Como o senhor analisa as tendências nutricionais observadas na população brasileira nos últimos anos (décadas), em relação à redução da prevalência de desnutrição energético-protéica (DEP) e ao aumento da prevalência do sobrepeso/obesidade?

M As duas tendências (redução da desnutrição e aumento do sobrepeso e da obesidade) fazem parte de um processo comum: a rápida transição nutricional que o Brasil apresenta. Essa transição específica na área de Nutrição está contextualizada num processo mais amplo - a transição epidemiológica do Brasil -, que conjuga processos de natureza diversificada: a rápida urbanização; o declínio substancial da natalidade após 1970, com diminuição do tamanho da família; a ascensão social e profissional da mulher; a melhoria das condições de saneamento; o êxito contra as doenças infecciosas; o novo perfil do mercado de trabalho, com aumento da escolaridade; a socialização das informações; o acesso mais amplo aos serviços e ações de saúde; a incorporação de novos hábitos alimentares e estilos de vida. No meio de todas essas transformações, um elemento de complicação - o apartheid social, marginalizando um quarto da população brasileira. É dentro desse contexto que se estruturam os dois pólos epidemiológicos do cenário nutricional do Brasil - o sobrepeso de velhos e adultos e a desnutrição das crianças.

F O senhor poderia comentar, em linhas gerais, a Portaria no 710, de 10/07/1999, do Ministério da Saúde, que dispõe sobre a chamada Política Nacional de Alimentação e Nutrição?

M Sou suspeito para comentar a portaria, porque sou um dos co-autores da proposta da Política Nacional de Alimentação e Nutrição. Foi o texto possível, num processo de consenso. Poderá ser um avanço, se não ficar apenas como mais um documento, incorporado à cultura de portarias inconseqüentes de nosso país.

F A atuação da esfera federal, a partir da extinção do INAN em 1997, vem correspondendo às suas perspectivas?

M Com a extinção do INAN, ficou um staff de quatro ou cinco combatentes, perdidos no tiroteio político e institucional da administração pública brasileira. Imagino Canudos em sua cena terminal. A alimentação representa, em média, $30 \%$ dos orçamentos domésticos. Os problemas carenciais (desnutrição, anemias, hipovitaminose A) atingem, estimativamente, $40 \%$ de nossa população. Metade das crianças que morrem tem desnutrição. A obesidade aumentou em $100 \%$ nos últimos 15 anos, na população adulta, arrastando, nessa onda epidêmica, o diabetes tipo 2 e as complicações cardiovasculares. É um peso epidemiológico considerá- 
vel, no quadro de saúde do Brasil. Miniaturizando o quadro de pessoal e vestindo em camisa de força seus movimentos, o governo está na contramão do curso dos acontecimentos e suas tendências. Os cinco do ex-INAN estão fazendo o que podem. São cinco dedos de uma mão enfraquecida - a mão da Política e dos Programas de Alimentação e Nutrição no Brasil.

\section{Agradecimentos}

Ao professor Ricardo Ventura Santos (Escola Nacional de Saúde Pública, Fundação Oswaldo Cruz), pelas valiosas críticas e sugestões.

\section{Referências e notas}

1 VASCONCELOS, F. A.G., 1999. Como Nasceram os Meus Anjos Brancos: A Constituição do Campo da Nutrição em Saúde Pública em Pernambuco. Tese de Doutorado, Rio de Janeiro: Escola Nacional de Saúde Pública, Fundação Oswaldo Cruz.

2 Informações extraídas fundamentalmente do texto da entrevista concedida pelo professor. Foram consultados também: COSTA, M. C. M. A. (org.), 1995. Quarenta Anos de Nutrição no Nordeste: Uma Retrospectiva. Recife: Editora Universitária da UFPE. COSTA, M. C. M. A. (org.), 1995. Memória Científica do Departamento de Nutrição e das Instituições Predecessoras (1950/1995). Recife: Editora Universitária da UFPE.

3 CASTRO, J., 1980. Geografia da Fome. 10a ed., Rio de Janeiro: Antares/Achiamé.

4 CASTRO, J., 1965. Geopolítica da Fome. 7ạ ed., São Paulo: Brasiliense.

5 CASTRO, J., 1967. Sete Palmos de Terra e um Caixão. 2ạ ed., São Paulo: Brasiliense.

6 JULIÃO, F., 1962. Que São as Ligas Camponesas? Rio de Janeiro: Civilização Brasileira.

7 AZEVÊDO, F. A., 1982. As Ligas Camponesas. Rio de Janeiro: Paz e Terra.

8 CASTRO, J., 1957. O Livro Negro da Fome. São Paulo: Brasiliense.
9 Líder do movimento das Ligas Camponesas na Paraíba, atuante na região de Sapé.

10 ICNND (Interdepartmental Committee on Nutrition for National Development), 1965. Northeast Brazil; Nutrition Survey, March-May 1963. Washington.

11 Na verdade, na época referida pelo professor, esses órgãos envolvidos no respectivo trabalho chamavam-se Fundação do Serviço Especial de Saúde Pública (FSESP) e Associação Nordestina de Crédito e Assistência Rural (ANCAR).

12 A primeira representação local do FISI no Brasil foi sediada, justamente, no ano de 1950, na cidade de João Pessoa, capital da Paraíba. Em 1951, entretanto, a sede foi transferida para o Rio de Janeiro. Portanto, foi a partir de 1950 que teve início a distribuição de alimentos por esse órgão no Nordeste brasileiro. Cf. COIMBRA, M., MEIRA, J. F. P. \& STARLING, M. B. L., 1982. Comer e Aprender: Uma História sobre a Alimentação Escolar no Brasil. Belo Horizonte: MEC/INAE. pp. 323-324.

13 BATISTA FILHO, M. \& ARRUDA, I. K. G., 1988. Eficácia e custos do tratamento da desnutrição energético-protéica. Revista do IMIP, 2:13-24.

14 BATISTA FILHO, M. \& BARBOSA, N. P., 1985. PróMemória: Alimentação e Nutrição no Brasil 19741984. Brasília: Ministério da Saúde/INAN. 